(c) 2022, The Authors. Published by Elsevier Inc. and Fass Inc. on behalf of the American Dairy Science Association ${ }^{\circledR}$. This is an open access article under the CC BY license (http://creativecommons.org/licenses/by/4.0/).

\title{
Economics of timed artificial insemination with unsorted or sexed semen in a high-producing, pasture-based dairy production system
}

\author{
D. P. Walsh, $\odot$ A. G. Fahey, ${ }^{*} \odot$ P. Lonergan, $\odot$ and M. Wallace $\odot$ \\ School of Agriculture and Food Science, University College Dublin, D04 V1W8, Dublin, Ireland
}

\begin{abstract}
This study used a stochastic simulation model to estimate the potential economic benefit of using timed artificial insemination (TAI) in combination with conventional unsorted (TCONV) and sexed (TSEX) semen in heifers only (TCONV-H, TSEX-H) and in both heifers and lactating cows (TCONV-HC, TSEX$\mathrm{HC}$ ) in a high-producing, pasture-based production system. The scenarios were compared with a conventional reproductive policy (CONV) in which heifers and cows were inseminated with conventional unsorted semen after estrus detection. Sensitivity analysis was also used to estimate the effect of hormone costs from TAI use on the profitability of each program relative to CONV. The mean annual ( \pm standard deviation) profit advantage $(\triangle \mathrm{PROF})$ over CONV for TCONV-H, TCONV-HC, TSEX-H, and TSEX-HC scenarios were $€ 3.90 /$ cow $\pm 4.65, € 34.11 /$ cow $\pm 25.69, € 13.96 /$ cow \pm 6.83 , and $€ 41.52 /$ cow \pm 42.86 , respectively. Combined application of both technologies was shown to return a greater annual $\triangle \mathrm{PROF}$ on average compared with that achievable from TAI alone. However, the risk of not returning a positive annual $\triangle \mathrm{PROF}$ varied across the scenarios with higher risk in TCONV-H and TSEXHC. Specifically, TCONV-H and TSEX-HC had a 24 and $18 \%$ chance, respectively, of not returning a positive annual $\triangle \mathrm{PROF}$. Sensitivity analysis showed that when hormone costs increased by $€ 10 /$ cow TCONV-H and TSEX-HC had a 38 and $23 \%$ chance, respectively, of not returning a positive annual $\triangle \mathrm{PROF}$. The range in $\triangle \mathrm{PROF}$ for TCONV policies was most sensitive to the TAI pregnancy rate and TSEX policies were most sensitive to the relative fertility achieved with sexed compared with unsorted semen. This study has shown TAI and sexed semen are complementary technologies that can increase genetic gain and profitability in a pasture-based, dairy production system.
\end{abstract}

Received July 27, 2021.

Accepted January 1, 2022.

*Corresponding author: Alan.Fahey@ucd.ie
Key words: timed artificial insemination, sexed semen, bioeconomics, stochastic model

\section{INTRODUCTION}

Reproductive performance is a fundamental driver of dairy herd profitability (Meadows et al., 2005; Galvão et al., 2013). In seasonal-calving pasture-based systems, the effect of poor reproductive performance is manifested in an increased spread in the annual calving profile, resulting in shorter lactations and suboptimal matching of pasture supply to peak feed demand. Additionally, long-term rates of genetic gain may be diminished in less fertile herds due to a lower selection intensity, as a greater proportion of heifer calves must be retained as herd replacements. Timed AI (TAI) facilitates maximum submission rate on the first day of the breeding season, thus improving the calving profile in seasonal pasture-based systems. Use of sexed semen (SS) can increase the selection intensity by decreasing the proportion of females required to produce a target number of dairy replacement heifers. However, the percentage of females that become pregnant from a single AI event ( $\mathbf{P} / \mathbf{A I})$ resulting from SS is consistently lower than that of unsorted semen (Maicas et al., 2019, 2020; Drake et al., 2020), increasing the costs associated with breeding and culling (Hutchinson et al., 2013). Sexed semen and TAI may complement each other, with TAI removing the need for labor intensive and potentially error-prone estrus detection, and SS increasing the rate of genetic gain through increased selection intensity on the dam side. Therefore, combined application of both technologies could return a higher profit advantage compared with that achievable from using either in isolation.

Increased knowledge of the reproductive physiology of the cow and the regulation of oocyte and embryo quality have led to the development of TAI programs that optimize P/AI (Carvalho et al., 2018). Numerous TAI programs exist, many now in use are variations on the Ovsynch protocol (Pursley et al., 1995) frequently including progesterone (P4; Pursley and Martins, 2011). Such programs increase the likelihood of earlier concep- 
tion compared with estrus detection and AI (Herlihy et al., 2011; Randi et al., 2018). Similarly, Giordano et al. (2011) concluded that TAI improved reproductive performance and resulted in a profit advantage over estrus detection and AI. However, Tenhagen et al. (2004) noted that the profit advantage of TAI is herd-specific and influenced by the basal fertility of the herd. Drake et al. (2020) found across 24 herds that the P/AI with TAI was influenced by semen type, with SS returning a relative $\mathrm{P} / \mathrm{AI}$ of $83 \%$ compared with that achieved using unsorted semen. However, the mean herd P/AI for TAI with SS in the bottom and top tertiles of herds ranged from 67 to $100 \%$ of the $\mathrm{P} / \mathrm{AI}$ for TAI with unsorted semen with the exact causes of this variation remaining undefined (Drake et al., 2020).

Sexed semen use can overcome the economic and welfare issues of low value male dairy calves and enhance calf sales revenue through use of beef semen on cows of lower genetic value not selected for breeding dairy herd replacements (Bittante et al., 2020). However, despite the potential benefits, adoption of SS has been hindered in seasonal pasture-based systems as a reduced $\mathrm{P} / \mathrm{AI}$ negatively affects the compactness of the calving period, a major driver of profitability (Hutchinson et al., 2013). Shalloo et al. (2014) estimated that a $1 \%$ increase in the 6 -wk calving rate in seasonal pasturebased systems increased net profit by $€ 822$ for a 100cow herd in Ireland. Cottle et al. (2018) noted that SS use can increase profitability per cow by an average of $6 \%$ relative to conventional semen in seasonal pasturebased dairy systems, but this advantage is highly sensitive to the relative $\mathrm{P} / \mathrm{AI}$ achieved with $\mathrm{SS}$ compared with conventional unsorted semen. Consequently, it is important to identify solutions to factors limiting reproductive performance from SS use.

Noonan et al. (2016) suggested using TAI to increase the P/AI of SS to offset poor fertility, accelerate genetic gain, and increase the proportion of heifers produced. For cows with a silent heat TAI can lessen the days open, specifically for cases that may be exacerbated by the reduced fertility from SS use. Together, both technologies have been shown to return a higher net present value than insemination based on detected estrus with unsorted or SS (Ojeda-Rojas et al., 2018). The economic effect of TAI with unsorted and SS has not been quantified in the context of seasonal-calving pasture-based systems. For such seasonal systems, TAI could further consolidate the calving period, synchronizing pasture supply and demand and thus reducing feed costs and increasing lactation length. In combination with SS, TAI use could advance the submission of the targeted heifers and cows to the farm mating start date, mitigating the risk of poorer P/AI from SS use and thus, limiting the deterioration in the subsequent calving pattern. In this context, TAI use with unsorted or SS may offer seasonal pasture-based dairy herds a profit advantage $(\boldsymbol{D P R O F})$ compared with their financial performance with estrus detection and AI with unsorted semen.

The analysis and evaluation of reproductive technologies under commercial conditions is challenged by the time lags between implementation of reproductive policies and observing their full economic impact, including genetic improvement. Simulation models are useful to overcome this limitation in economic-based analyses as they allow adaptations to be evaluated using in silico representation of the bio-physical and economic processes within the farming system. In this context, bioeconomic models can augment the analysis of data from controlled trials, enabling the testing of additional scenarios where experimentation is unfeasible for reasons of practicality or cost.

The objective of this study was to evaluate the economics of TAI with unsorted (TCONV) or sexed semen (TSEX) in comparison to estrus detection and insemination with conventional unsorted semen in a seasonal, pasture-based, high-producing dairy production system. The study also sought to simulate the effects of variability in key market prices and technical parameters to provide a robust quantification of the distribution of the annual $\triangle \mathrm{PROF}$, thereby assessing financial risks of adoption of these reproductive technologies.

\section{MATERIALS AND METHODS}

\section{University College Dublin Lyons Dairy Simulation Model}

We used a stochastic whole-farm simulation model to evaluate the bio-physical and financial effects of TCONV and TSEX reproductive technologies. A brief explanation of the University College Dublin Lyons Dairy Simulation Model is provided here for context, and a more detailed description of the methodology is documented by Walsh et al. (2021). The model operates on a monthly timestep to provide a comprehensive framework that integrates animal inventory, milk production, feed requirements and supply, genetic gain, land, and labor utilization of a high-producing pasturebased dairy production system (see Figure 1). Feed requirements were calculated to meet the energy requirements for maintenance, lactation, pregnancy, and BW change throughout lactation (Jarrige, 1989). The default parameters of the simulated farm were specified from University College Dublin, Lyons Systems Herd 


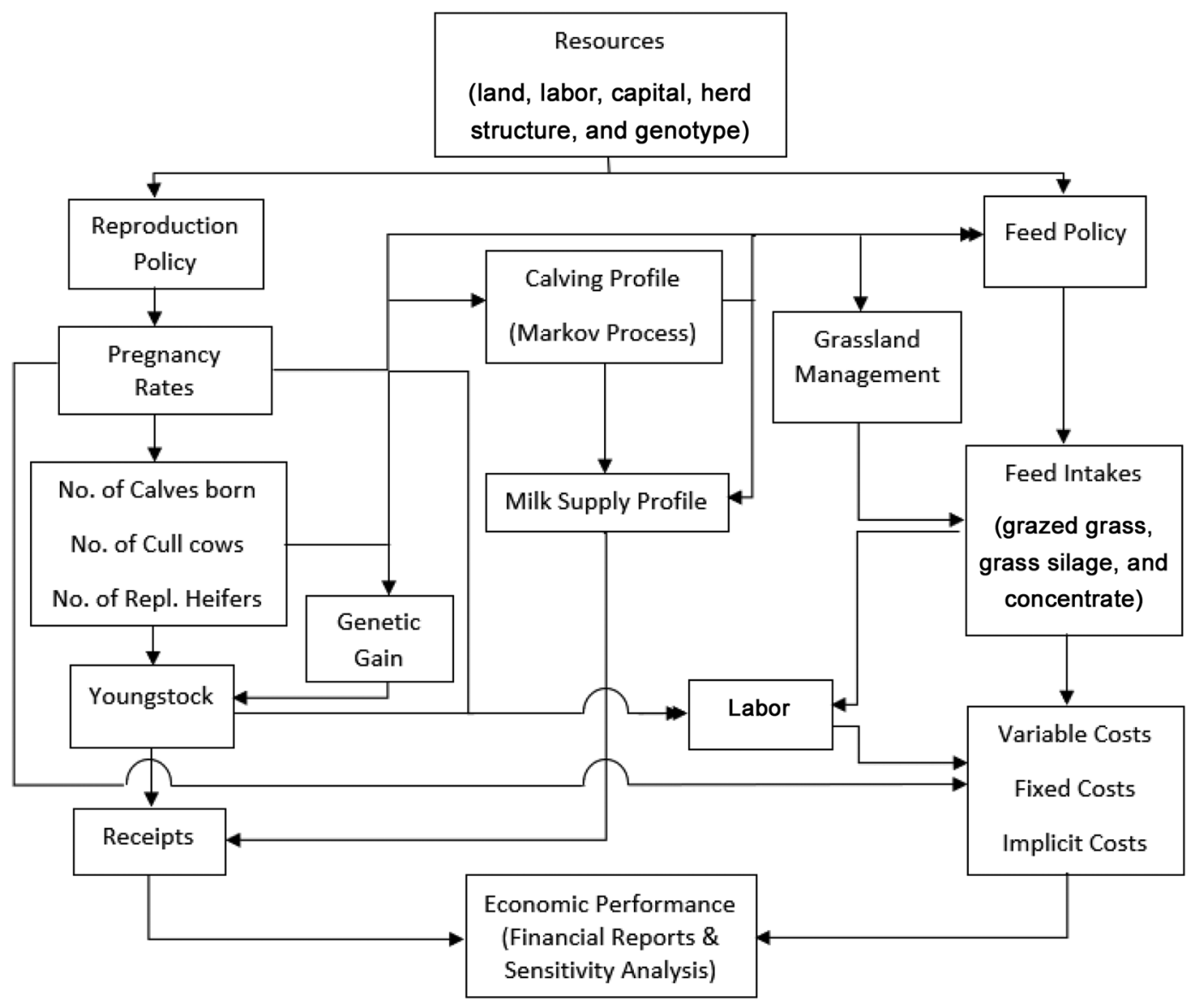

Figure 1. Flowchart illustrating the major components of the University College Dublin, Lyons, dairy simulation model. Repl. = replacement.

at Celbridge, Naas, Co. Kildare. The average milk yield per cow was $7,466 \mathrm{~kg}$ and $595 \mathrm{~kg}$ of milk solids (fat and protein) with a whole farm stocking rate of 2.4 livestock units/ha, representative of a high-producing, pasturebased production system in Ireland. The system focuses on the efficient utilization of grazed grass and strategic supplementation of concentrates with a total grass production of approximately $13 \mathrm{t} /$ ha per year. Grazed grass and grass silage account for $75 \%$ of the diet (on a DM basis) with $1.5 \mathrm{t}$ (1.3 t of DM) of concentrates fed in the milking parlor. The grazing season is dependent on grass supply and soil conditions but generally extends from February to early November.

The analysis assumed a fixed herd size of 80 cows, based on the average herd size in Ireland (Donnellan et al., 2020). The average yield for first, second, and third parity cows was $0.72,0.86$, and 0.96 of the mature (fourth parity and greater) milk yield (O'Sullivan et al., 2019). Land area of the farm was 38.6 ha, and land could be rented or leased out at prevailing land market rental prices per hectare as required. The opportunity cost of land was $€ 474$ per hectare based on current rent for good quality pasture (Society of Chartered Surveyors Ireland and Teagasc, 2020). Fixed costs (machinery operating expenses, machinery depreciation, farm maintenance, phone, electricity, insurance, and professional fees) were based on average values for dairy farms from the National Farm Survey (Donnellan et al., 2020). Infrastructure costs such as housing of heifers and cows were derived from Ryan (2018) and assumed to be at the mid-point of their write-down period. Sales receipts (milk, calf, and cull cow) and variable costs (purchased concentrates, contractor charges, and fertilizer) were based on current prices (Table 1).

Risk analysis and assessment were implemented through Monte Carlo sampling using @risk (Palisade Corp.). The stochastic components included pregnancy rates as well as input and output price variables that were deemed to be most pertinent to the economic outcomes of the reproductive scenarios. Details of the probability distributions for the sensitivity parameters within the model are shown in Table 1. To account 
Table 1. Parameters of the input distributions (mode, SD, minimum, and maximum values) used in the risk modeling

\begin{tabular}{|c|c|c|c|c|c|}
\hline Input parameter & Mode & SD & Minimum & Maximum & Source \\
\hline Timed AI 21-d pregnancy $\operatorname{rate}^{2}(\%)$ & 127 & 8 & 100 & 140 & $\begin{array}{l}\text { Herlihy et al. (2011); Randi et al. (2018); } \\
\text { Borchardt et al. (2018) }\end{array}$ \\
\hline Beef bull calf ( $€ /$ head $)$ & 257 & 39 & 136 & 326 & Irish Farmers Journal (2019) \\
\hline Beef heifer calf $(€ /$ head $)$ & 229 & 47 & 82 & 308 & Irish Farmers Journal (2019) \\
\hline Dairy bull calf ( $€ /$ head) & 37 & 11 & 0 & 76 & Irish Farmers Journal (2019) \\
\hline Cull cow ( $€ / \mathrm{kg}$ dressed carcass) & 2.95 & 0.33 & 1.96 & 3.56 & Bord Bia (2021) \\
\hline Milk fat price $(€ / \mathrm{kg})$ & 3.88 & 0.44 & 2.81 & 4.95 & CSO (2021) \\
\hline Milk protein price $(€ / \mathrm{kg})$ & 7.00 & 0.78 & 5.06 & 8.90 & CSO (2021) \\
\hline 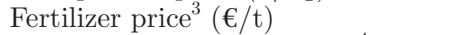 & 356 & 34 & 216 & 358 & CSO (2021) \\
\hline Standard deviation of index ${ }^{4}(€)$ & 119 & 50 & 0.00 & 224 & ICBF (2021) \\
\hline
\end{tabular}

${ }^{1}$ The relative pregnancy rates of sexed to conventional unsorted semen.

${ }^{2}$ The relative 21-d pregnancy rates of timed AI relative to conventional estrus detection.

${ }^{3}$ Reference fertilizer price, per tonne, of composition $25 \%$ N, $5 \%$ P, $10 \% \mathrm{~K}$.

${ }^{4}$ Assumed to have a normal distribution.

for co-variation between stochastic variables, correlations were incorporated between milk fat and protein price $(€ / \mathrm{kg})$, beef heifer and beef bull calf price, and beef bull and dairy bull calf price of $0.92,0.82$, and 0.57, respectively (Irish Farmers Journal, 2019; Central Statistics Office, 2021). Correlations among other stochastic variables were inconsequential and accordingly they were assumed to be independently distributed.

Capital costs comprised of infrastructure costs and working capital, including the value of the livestock. An imputed cost of capital of 5\% was used as this is typical of the average annual interest rate in Ireland during the reference period of the study (Central Bank of Ireland, 2018). Labor requirements per cow were modeled by task category, using data from Deming et al. (2018) to account for variability in milking time, management, winter feeding, veterinary and breeding tasks. Labor time for milking was calculated according to the milk yield using data from Deming et al. (2018) and O'Sullivan et al. (2019). All replacement heifers were reared on farm and monthly labor coefficients were derived from Redman (2016) and aggregated to a per replacement heifer basis. Labor coefficients were also associated with estrus detection, AI, and animal health-related tasks. The opportunity cost of all labor was assumed to be $€ 15 / \mathrm{h}$ (Teagasc, 2018). Economic profit was used as an all-inclusive measure of financial performance, accounting for the implicit and explicit costs of all resources used in production to generate revenue (Stewart, 2003).

\section{Reproductive Performance and Survival}

The 12-wk breeding period and survival rates of the herd were simulated using a 2-stage, hierarchical Mar- kov chain. In the first stage, the cumulative calving rate for the herd was calculated sequentially using probabilities for heat detection $(h)$ and conception rates $(c)$ at each service. The breeding period was modeled as successive 21-d time intervals $(s)$ commencing on May 1 each year. Accordingly, the estimated proportion $\left(p_{s}\right)$ of the herd becoming pregnant in the first 21-d of the breeding period was the product of the proportion of the females observed in heat $\left(h_{s}\right)$ times the effective conception rate $\left(c_{s}\right)$ per insemination:

$$
p_{s}=h_{s} \cdot c_{s} \text {. }
$$

The parameter $c_{s}$ is conception rate net of early embryo loss based on Hutchinson et al. (2013). The share of the herd becoming pregnant in the second and subsequent time intervals was calculated using sequential equations of the form:

$$
\begin{array}{ll}
p_{s+1}= & h_{s+1}\left(1-p_{s}\right) c_{s+1} \\
\vdots & \vdots \\
p_{s+n}= & h_{s+n}\left(1-p_{s}-p_{s+1} \ldots-p_{s+n-1}\right) c_{s+n} .
\end{array}
$$

At each time stage, these expressions accounted for the proportions of females already pregnant in the preceding period(s). Consequently, the overall pregnancy rate $\left(r_{t}\right)$ of the herd at the end of the breeding period in year $t$ was the sum of the incremental pregnancy rates of the sequence of 21-d intervals:

$$
r_{t}=p_{s}+p_{s+1}+\ldots+p_{s+n} \text {. }
$$

In the treatment scenarios the $c_{s}, c_{s+1}, \ldots c_{s+n}$ were recalculated in each iteration because the 21-d preg- 
nancy rate of TAI as a percentage of conventional and the relative $\mathrm{P} / \mathrm{AI}$ of $\mathrm{SS}$ to conventional semen were modeled as probability distributions.

The second stage of the Markov process estimated annual survival rates and the monthly calving profile for the herd. In matrix notation, this Markov model is expressed as

$$
\mathbf{N}_{t}=\mathbf{P N}_{t-1}
$$

where $\mathbf{N}_{t}=\left(n_{1 t}, \ldots . n_{m t}\right)$ is an $(m \times 1)$ column vector comprising the numbers of females calving in each month and the number to be culled in year $t$. $\mathbf{P}$ is a stochastic $(m \times m)$ matrix of transition probabilities $p_{i j}$ $\geq 0$ and satisfying $\sum_{i=1}^{m} p_{i j}=1$, expressing the probabilities of females calving in each month or being culled in year $t$ based on their state in the previous year $(t-1)$. In addition, the elements $\mathbf{P}$ are also a function of the pregnancy rates $(r)$ in year $t-1$ from Equation 3. Because the elements of $\mathrm{P}$ are calculated based on 21-d pregnancy rates, the $p_{i j}$ elements are mapped to the monthly time steps according to the timing of pregnancies in each 21-d interval. Accordingly, the $p_{i j}$ elements of matrix $\mathbf{P}$ take the form

$$
p_{s j t}=f\left(i, j, r_{t-1}\right) \text {. }
$$

Consequently, the transition probabilities in matrix $\mathbf{P}$ are nonstationary as the $p_{i j}$ coefficients are determined by $r_{t-1}$, which vary in model simulations based on the distribution of the conception rates $\left(c_{s}\right)$. The transition probabilities in matrix $\mathbf{P}$ accounted for rates of survival and likelihood of slippage in month of calving. Accordingly, the model simulated variations in the timing of pregnancies under reproductive strategies. For example, using a TAI protocol, pregnancies could be concentrated early in a 21-d interval, whereas under conventional AI. pregnancies occurred, on average, at the mid-point of a 21-d cycle. Consequently, the potential for TAI to achieve greater compaction of the calving distribution could be quantified.

The initial vector $\mathbf{N}$ (year $t=0$ ) for the calving profile comprised $15,52,23$, and $10 \%$ of the cows calving in the months of January, February, March, and April, respectively. At each model iteration, the Markov chain was solved for a 12-yr time horizon, by which time the herd profile vector $(\mathbf{N})$ converged to a steady state. The financial impact of each scenario was evaluated at this stationary position to represent a long-term status when affected herd parameters (parity structure, calving profile, culling rates) had stabilized under each breeding policy.
Losses from the herd were quantified in an exit state composed of mortality and animals culled due to calving slippage, infertility, or voluntary reasons. Specifically, cows that calved later than April in the previous year were not rebred and were assumed to be culled at the end of their current lactation to maintain the seasonality of the system. Also, added to the cull category were the number of empty cows at the end of the breeding period determined in the first stage Markov chain $\left(1-r_{t}\right.$, see Equation 3). The transition probabilities included a fixed annual mortality rate $(3 \%)$ and an assumed rate of voluntary culling for nonfertility factors (Maher et al., 2008). Voluntary culling was modeled as an inverse linear function of the rate of culling due to infertility, truncated between 5 and $8 \%$. This reflected standard management practice for increased selective culling as reproductive performance improves (Souza et al., 2013).

The calving profile of heifers was calculated based on their birth dates, submission age, and pregnancy rates. Only heifers born in January and February of the calving period were retained as dairy replacements to prevent slippage of the overall calving pattern. The model assumed that all replacement heifers had reached puberty and were eligible for breeding by approximately 14 to $16 \mathrm{mo}$ of age, and subsequently calved for the first time at approximately 23 to 25 mo of age. Male calves and surplus dairy heifer calves were sold at 1 mo of age. Calf survival to 1 mo of age was assumed to be $95 \%$ of successful live births (Irish Cattle Breeding Federation, 2020). In each scenario simulation, the model targeted that sufficient heifer calves were produced to meet the replacement heifer requirements to maintain a fixed herd size, accounting for the occurrence of barrenness and mortality over the 24-mo rearing period. The model allows the purchase of additional heifers only if insufficient heifers are produced within the herd.

\section{Genetic Gain}

Genetic gain was modeled in a similar way to Walsh et al. (2021). The financial contribution of genetic gain was simulated as the change in the herd economic merit based on Ireland's Economic Breeding Index for dairy cattle. Sexed semen may increase rates of genetic gain as increased selection intensity can be placed on the proportion of females to be bred $\left(p_{f}\right)$, so that female progeny and their descendants have higher genetic and phenotypic merit. Standardized selection intensities of breeding females $\left(i_{f t}\right)$ were approximated by the expression of Madalena and Junqueira, 2004:

$$
i_{f t}=0.8+0.41 \ln \left[\left(1 / \rho_{f t}\right)-1\right] .
$$


The genetic superiority of selected breeding females contributes to profit through the response to selection which is estimated by truncation on a breeding index, expressed as the economic breeding value $\left(\pi_{\text {index }}\right)$ :

$$
\Delta G=i_{f t} \cdot \pi_{\text {index }},
$$

where $\Delta G$ is the rate of genetic gain.

However, genetic improvement occurs over several years as the superior genes of the replacement heifers are inherited through the successive generations in the milking herd. Therefore, the expression of a breeding female's superior genes in the milking herd is a function of the survival rate and their age at first calving ( afc), assumed to be 23 to 25 mo. The survival of a lactating female of generation $g$, from age at first calving to a given year $t$ was defined as

$$
S_{g t}=\prod_{t=a f c}^{t} \alpha_{t},
$$

where $\alpha_{t}$ is the annual survival probability for a lactating female in year $t$.

The genetic expressions for the offspring of a breeding female of generation $g$ and year $t$ were represented as

$$
O_{g t}=S_{g-1, t-2} \cdot \rho_{f t} \cdot r_{t},
$$

where $r_{t}$ is the calving rate as previously defined in Equation 3.

The financial contribution of the replacement heifers' superior genes through the successive generations was accounted for using discounting methods and was a function of the survival rate within the herd. A discount rate $(\delta)$ of $5 \%$ was used to calculate the cumulative discounted expressions $(N)$ of the replacement heifer and her descendants with maximum values of $t=12$ and $g=3$ assumed in the derivation of $N$.

$$
N=\sum_{t=a f c}^{T} \sum_{g=1}^{G}\left(\frac{1}{(1+\delta)^{t}}\left(S_{g t}+O_{g t}\right)\right) .
$$

The added genetic gain from the descendants to economic profit was then expressed by truncation on a total profit index (Ireland's Economic Breeding Index) from selected replacement females by

$$
1 / 2\left(N \cdot i_{f t} \cdot \pi_{\text {index }}\right) .
$$

In dairy systems, genetic inheritance from an initial insemination is passed through successive generations by females only within the population. Consequently, the frequency would be halved with each generation.

\section{Reproductive Scenarios}

A $2 \times 2$ factorial scenario design was used to evaluate TAI with either TCONV or TSEX and treatment applied to heifers only or both heifers and cows. The scenarios were compared with a conventional reproductive policy in which heifers and cows were inseminated with unsorted semen after detected estrus. Therefore, 5 breeding strategies were modeled: (1) TAI in heifers only, with heifers and cows inseminated with unsorted semen (TCONV-H); (2) TAI in both heifers and cows and inseminated with unsorted semen (TCONV-HC); (3) TAI in heifers only with heifers inseminated with sexed semen and cows inseminated with unsorted semen (TSEX-H); (4) TAI in both heifers and cows inseminated with sexed semen (TSEX-HC); and (5) a baseline scenario in which heifers and cows were inseminated with unsorted semen after estrus detection (CONV). It was assumed that TAI was only administered a single time at the start of the breeding period for first service only and for all females selected to be bred. A P4-Ovsynch protocol was chosen as this has been shown, including in several recent studies from Ireland, to result in excellent fertility (Randi et al., 2018; Sánchez et al., 2018). It is now well accepted that inclusion of a $\mathrm{P} 4$ device, or use of a strategy to induce elevated P4 (e.g., induction of an accessory corpus luteum), into a standard Ovsynch protocol is beneficial due to the known positive effects of elevated P4 during the growth of the ovulatory follicle (Pursley and Martins, 2011; Rivera et al., 2011). An additional injection of $\mathrm{PGF}_{2 \alpha}$ was included and administered on $\mathrm{d} 8$ as it was found to increase the $\mathrm{P} / \mathrm{AI}$ by 4.6 percentage units compared with cows receiving a conventional Ovsynch protocol, which included only one $\mathrm{PGF}_{2 \alpha}$ injection on $\mathrm{d}$ 7 (Borchardt et al., 2018). A P4-Ovynch program minimizes animal handling and the complexity of the TAI protocol. Specifically, increasing the number of sequential injections required for a heifer or cow to complete a TAI protocol reduces the probability of compliance and increases costs and labor associated with reproductive management. For all services, heifers and cows were artificially inseminated. The reproductive performance of CONV was defined as a $95 \%$ estrus detection rate and a $55 \% \mathrm{P} / \mathrm{AI}$ (the percentage of females that became pregnant from a single AI event). In addition, the $\mathrm{P} /$ AI for nonlactating heifers was $5 \%$ greater than cows to account for their inherent higher fertility (Butler et al., 2014). These fertility parameters were based on data from University College Dublin, Lyons systems herd at Celbridge, Naas, Co. Kildare (University College Dub- 
lin, 2020) and they reflect efficiency levels achieved by the top $5 \%$ of benchmarked dairy herds in Ireland. The other scenarios were evaluated relative to the baseline herd fertility state of $\mathrm{CONV}$ which corresponded to a herd replacement rate of $23 \%$. The annual $\triangle \mathrm{PROF}$ was calculated as the increase in economic profit from the use of TCONV or TSEX relative to the reference scenario of estrus detection and insemination with conventional unsorted semen (CONV). Each scenario comprised of 100,000 iterations. At each iteration the steady-state herd parameters (parity structure, replacement rate, calving spread, rate of genetic gain) were estimated at yr 12 of the simulated time horizon, when the effect of each reproductive scenario was fully realized. Financial performance was then evaluated at the steady-state values for the herd parameters, in yr 12 . This approach enabled consistent and tractable comparisons of the reproductive scenarios, abstracting from the short-term adjustments in the 'bedding-in' phase of each management strategy.

To maintain the seasonality of the system a maximum of 3 services were assumed. The proportion of the herd served to dairy unsorted or SS in each scenario was optimized to ensure that sufficient dairy heifer calves were available to meet the demand for replacement heifers in the herd. Specifically, the distributions for the $\mathrm{P} / \mathrm{AI}$ of TAI and the SS P/AI as a percentage of conventional AI were set to their minimum values (Table 1). Then, with the distributions at their worstcase values, the required proportion of the herd served with dairy unsorted or SS was solved to ensure that the number of heifers available matched the replacement requirements of the herd. In all scenarios, females received common management as a group with dairy unsorted or SS used at the start of the breeding period until the replacement requirements of the herd were met. Thereafter, in the following weeks of the breeding period, any subsequent insemination rounds were to beef semen to maximize calf sales value.

\section{Scenario Costs}

The total hormone cost of a modified P4-Ovsynch synchronization protocol was estimated at $€ 41$ per animal treated. Heifers and cows submitted to TAI received an 8-d progesterone-releasing intravaginal device (PRID; containing $1.55 \mathrm{~g}$ of P4) with $100 \mu \mathrm{g}$ of gonadorlelin diacetate tetrahydrate $(\mathrm{GnRH})$ at PRID insertion, an injection of $\mathrm{PGF}_{2 \alpha}$ (Enzaprost, $25 \mathrm{mg}$ of dinoprost trometamol) $24 \mathrm{~h}$ before PRID removal, an additional injection of $\mathrm{PGF}_{2 \alpha}$ at PRID removal and GnRH $32 \mathrm{~h}$ after PRID removal. Timed AI of conventional unsorted (TCONV) or sexed (TSEX) dairy semen was carried out $16 \mathrm{~h}$ after the second $\mathrm{GnRH}$ injection

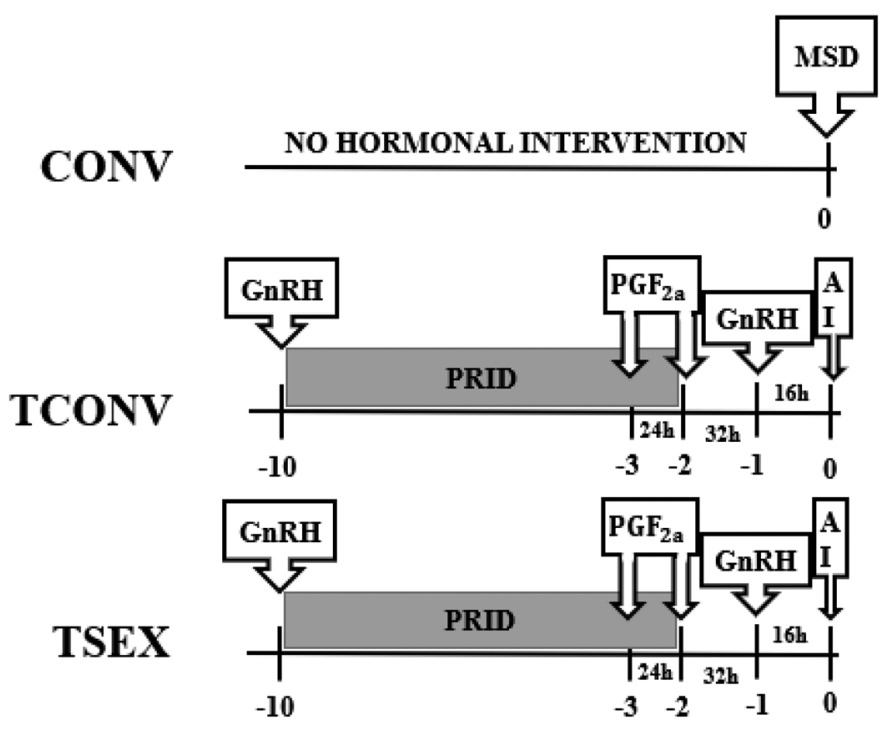

Figure 2. Schematic diagram of the synchronization protocols used in the analysis. Heifers and cows were bred at detected estrus (mating start date, MSD) with no hormonal treatment (CONV), an 8-d progesterone-releasing intravaginal device (PRID) with GnRH at PRID insertion, a luteolytic dose of $\mathrm{PGF}_{2 \alpha}$ at $24 \mathrm{~h}$ before PRID removal with an additional dose of $\mathrm{PGF}_{2 \alpha}$ at PRID removal, $\mathrm{GnRH} 32 \mathrm{~h}$ after PRID removal with timed AI performed with conventional unsexed (TCONV) or sexed (TSEX) dairy semen 16 h later.

(Figure 2). The prices of GnRH (€6.80 \pm 1.62$), \mathrm{PGF}_{2 \alpha}$ $(€ 6.20 \pm 0.78)$, and a PRID (€15.00 \pm 2.37$)$ were average commercial prices per dose and insert, respectively, obtained through consultation with private veterinary practices in Ireland. The cost per straw of dairy SS, conventional unsorted dairy and beef semen were set at $€ 38$, €20, and €13, respectively (Cottle et al., 2018; Progressive Genetics, 2021). It was assumed that TAI use eliminated the labor time associated with estrus detection for that insemination. The farmer's labor time to apply hormonal treatments was estimated at $1 \mathrm{~min}$ per injection and 3 min per PRID insert based on the assumptions of Galvão et al. (2013) and Stangaferro et al. (2018). For all other services, where no hormonal treatment was given the labor time for estrus detection was set using data from Deming et al. (2018).

In a European context the hormonal costs of TAI are relatively expensive compared with the US market, which reduces the potential annual $\triangle \mathrm{PROF}$ from its use (Ricci et al., 2020). Therefore, we conducted a sensitivity analysis to estimate the effect of hormone costs on the profitability of the program on average, relative to CONV. We incrementally decreased and increased the hormone costs by $€ 10$ per heifer and cow treated to determine their impact on the potential annual $\triangle \mathrm{PROF}$ from their use. The range of hormone cost values considered reflected the minimum and maximum calculated potential prices charged by vet- 
erinary practices for a modified P4-Ovsynch protocol. The analysis used 3 simulations (10,000 iterations each) to give a comprehensive annual $\triangle \mathrm{PROF}$ while allowing the assumed critical input parameters maintain their stochasticity.

\section{RESULTS}

The mean economic profit per cow and per hectare increased with the adoption of TAI and unsorted or SS (see Table 2). However, TAI with SS returned a greater economic profit in comparison to TAI with conventional unsorted semen. For the 5 reproductive programs TSEX-HC returned the greatest economic profit per cow (€462.28) followed by TCONV-HC (€454.88), TSEX-H (€434.72), TCONV-H (€424.67), and CONV (€420.77). Key descriptive statistics for the annual $\triangle \mathrm{PROF}$, which represents the increase in economic profit from TCONV or TSEX relative to CONV are also shown in Table 2. The greatest annual $\triangle \mathrm{PROF}$ was achieved in TSEX-HC followed by TCONV-HC, TSEX-H, and TCONV-H. At the fifth percentile, the annual $\triangle \mathrm{PROF}$ distributions per cow and per hectare were negative for TCONV-H, TCONV-HC, and TSEX$\mathrm{HC}$.
Details of the physical performance for each reproductive policy are shown in Table 3. Across the reproductive policies, negligible differences existed between diet composition with grazed grass and grass silage representing $79 \%$ of total diet DM composition across all the scenarios. Milk production for the herd increased across all scenarios relative to CONV. It was found that TCONV-HC had reduced services per pregnancy relative to TSEX-HC, which further concentrated the calving pattern. The number of replacement heifers bred relative to CONV remained similar for TSEX-H and reduced for TCONV-H, TCONV-HC, and TSEXHC. The number of heifer calves produced was highest for TSEX-HC followed by TCONV-HC, TSEX-H, TCONV-H, with CONV producing the fewest. Across the scenarios, TSEX-H produced the most beef-cross calves followed by TSEX-HC, TCONV-H, CONV, and TCONV-HC, respectively. Our analysis showed that genetic gain increased across all reproductive policies compared with CONV; however, the increase was greatest for TSEX-HC followed by TCONV-HC, TSEX-H, and TCONV-H, respectively. The proportion of heifer calves retained for breeding was highest for CONV followed by TCONV-H, TSEX-H, TCONVHC, and TSEX-HC. Consequently, selection intensity

Table 2. Descriptive statistics for simulated economic profit and economic profit distributions of the profit advantage $(\triangle \mathrm{PROF})^{1}$ per cow and per hectare for estrus detection and insemination with unsorted semen $(\mathrm{CONV})$, timed AI (TAI) in heifers only with heifers and cows inseminated with unsorted semen (TCONV-H), TAI in both heifers and cows and inseminated with unsorted semen (TCONV-HC), TAI in heifers only with heifers inseminated with sexed semen and cows inseminated with unsorted semen (TSEX-H), and TAI in both heifers and cows inseminated with sexed semen (TSEX-HC)

\begin{tabular}{|c|c|c|c|c|}
\hline Group & Mean & SD & 5 th percentile & 95th percentile \\
\hline \multicolumn{5}{|l|}{$\overline{\mathrm{CONV}(€)}$} \\
\hline Per cow & 420.77 & 234.37 & 32.53 & 806.45 \\
\hline Per ha & 816.76 & 454.95 & 63.15 & $1,565.42$ \\
\hline \multicolumn{5}{|l|}{ TCONV-H $(€)$} \\
\hline Per cow & 424.67 & 234.76 & 36.28 & 810.96 \\
\hline Per ha & 828.40 & 457.96 & 70.71 & $1,581.74$ \\
\hline$\triangle \mathrm{PROF}(€ /$ cow $)$ & 3.90 & 4.65 & -3.81 & 11.55 \\
\hline$\triangle \mathrm{PROF}(€ / \mathrm{ha})$ & 11.64 & 10.73 & -2.56 & 29.48 \\
\hline \multicolumn{5}{|l|}{ TSEX-H (€) } \\
\hline Per cow & 434.72 & 234.96 & 45.58 & 821.05 \\
\hline Per ha & 845.23 & 456.87 & 88.60 & $1,596.22$ \\
\hline$\triangle \mathrm{PROF}(€ /$ cow $)$ & 13.96 & 6.83 & 2.96 & 25.49 \\
\hline$\Delta \mathrm{PROF}(€ / \mathrm{ha})$ & 28.47 & 14.99 & 4.43 & 53.84 \\
\hline \multicolumn{5}{|l|}{ TCONV-HC $(€)$} \\
\hline Per cow & 454.88 & 239.86 & 58.66 & 849.38 \\
\hline Per ha & 898.55 & 474.26 & 115.64 & 1.679 .03 \\
\hline$\triangle \mathrm{PROF}(€ /$ cow $)$ & 34.11 & 25.69 & -12.11 & 72.45 \\
\hline$\triangle \mathrm{PROF}(€ / \mathrm{ha})$ & 81.79 & 57.56 & -18.84 & 171.13 \\
\hline \multicolumn{5}{|l|}{ TSEX-HC $(€)$} \\
\hline Per cow & 462.28 & 240.17 & 65.54 & 855.69 \\
\hline Per ha & 901.32 & 469.23 & 127.69 & 1.671 .04 \\
\hline$\triangle \mathrm{PROF}(€ /$ cow $)$ & 41.52 & 42.86 & -30.58 & 111.40 \\
\hline$\triangle \mathrm{PROF}(€ / \mathrm{ha})$ & 84.56 & 90.26 & -65.67 & 233.05 \\
\hline
\end{tabular}

${ }^{1}$ The difference in economic profit from the TAI with or without sexed semen scenarios compared with the reference reproductive policy consisting of estrus detection and conventional unsorted semen. It measures the financial advantage, if any, of TAI with or without sexed semen over conventional estrus detection with unsorted semen. 
Table 3. Summary of key technical simulated outputs of models simulations for estrus detection and insemination with unsorted semen (CONV), for timed AI (TAI) in heifers only with heifers and cows inseminated with unsorted semen (TCONV-H), TAI in both heifers and cows and inseminated with unsorted semen (TCONV-HC), TAI in heifers only with heifers inseminated with sexed semen and cows inseminated with unsorted semen (TSEX-H), and TAI in both heifers and cows inseminated with sexed semen (TSEX-HC) ${ }^{1}$

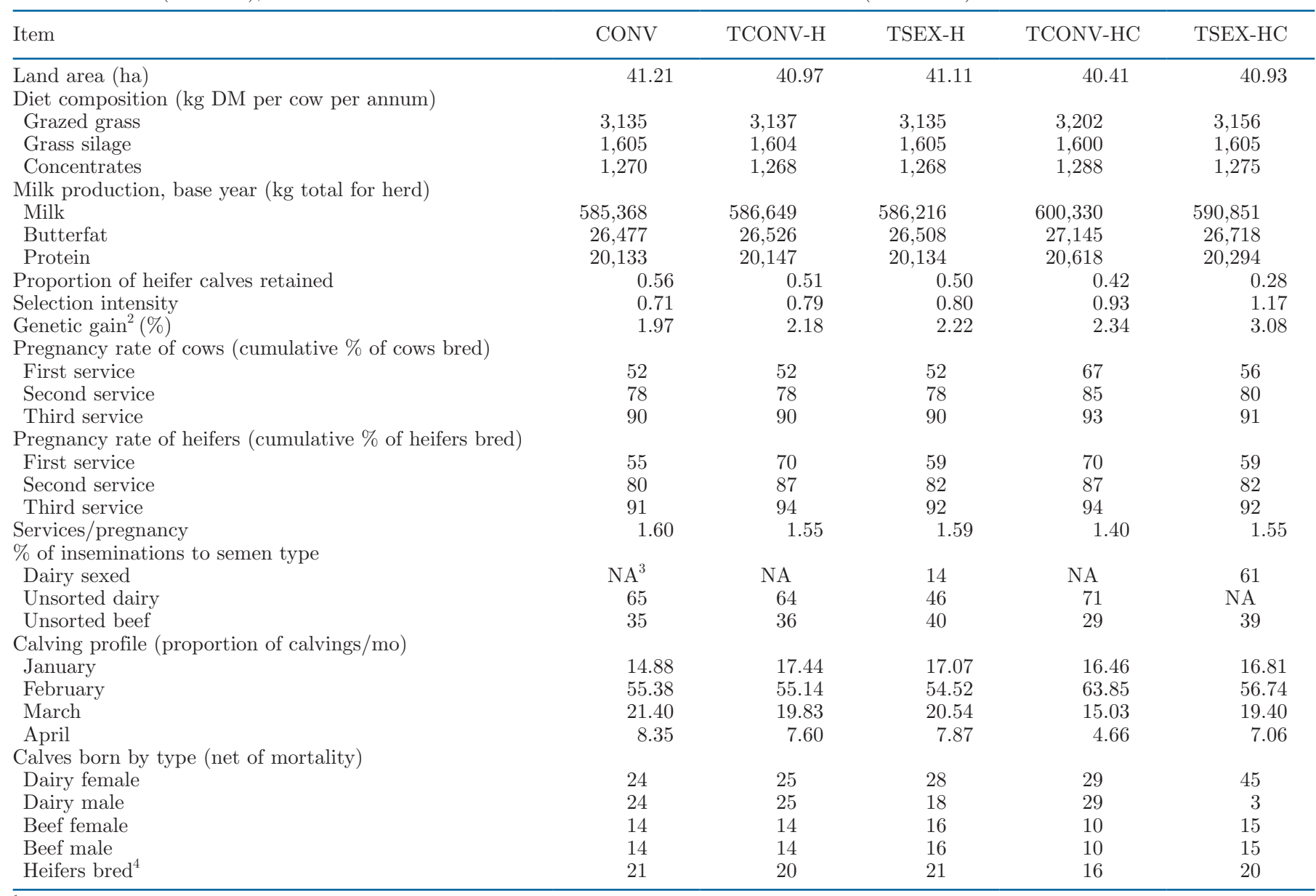

${ }^{1}$ Fixed dairy herd size of 80 cows in all scenarios.

${ }^{2}$ The percentage contribution of genetic gain to revenue.

${ }^{3} \mathrm{NA}=$ Not applicable.

${ }^{4}$ Replacement heifers bred.

was highest for TSEX-HC followed by TCONV-HC, TSEX-H, TCONV-H, and CONV. Relative to CONV selection intensity increased by $40,22,11$, and $10 \%$ for TSEX-HC, TCONV-HC, TSEX-H, and TCONV-H, respectively.

Adoption of TCONV and TSEX increased milk sales relative to CONV (see Table 4). A larger number of dairy heifer calves increased calf sales (relative to CONV) by $€ 4,980$ in TSEX-HC and by $€ 1,547$ in TSEX-H. In comparison, TCONV-H produced similar, and TCONV-HC produced less higher value beef-cross calves and more dairy calves than CONV. Consequently, TCONV-H and TCONV-HC had marginal difference in calf sales of $€ 72$ and $-€ 26$, respectively, relative to CONV. This was due to the increased proportion of the herd conceiving in earlier dairy insemination rounds of the breeding period. Calf sales represented $6.05 \%$ of revenue in TSEX-HC; in comparison, calf sales represented $4.73,4.13,4.10,4.13$, and $4.04 \%$ in TSEX-H, TCONV-H, CONV, and TCONV-HC, respectively. Cull cow sales were reduced in all the reproductive policies relative to CONV. In comparison to CONV, TCONV-HC had the lowest cull cow sales with an overall decrease of $20 \%$ followed by $7 \%, 4 \%$ and $2 \%$ for TSEX-HC, TCONV-H and TSEX-H, respectively. The percentage contribution of genetic gain to revenue was highest in TSEX-HC followed by TCONV-HC, TSEX$\mathrm{H}$, TCONV-H, and CONV, respectively. Relative to CONV, the monetary impact of genetic gain increased across the reproductive policies by $€ 2,819$, €920, €624, and $€ 495$ in TSEX-HC, TCONV-HC, TSEX-H, and TCONV-H, respectively. The increased return from 
Table 4. Summary of key financial simulated outputs of models simulations for estrus detection and insemination with unsorted semen (CONV), for timed AI (TAI) in heifers only with heifers and cows inseminated with unsorted semen (TCONV-H), TAI in both heifers and cows and inseminated with unsorted semen (TCONVHC), TAI in heifers only with heifers inseminated with sexed semen and cows inseminated with unsorted semen (TSEX-H), and TAI in both heifers and cows inseminated with sexed semen (TSEX-HC) ${ }^{1}$

\begin{tabular}{|c|c|c|c|c|c|}
\hline Item & CONV & TCONV-H & TSEX-H & TCONV-HC & TSEX-HC \\
\hline \multicolumn{6}{|l|}{ Receipts $(€)$} \\
\hline Milk sales & 200,956 & 201,280 & 201,163 & 205,829 & 202,719 \\
\hline Calf sales & 9,420 & 9,492 & 10,967 & 9,394 & 14,400 \\
\hline Cull sales & 14,744 & 14,112 & 14,487 & 11,732 & 13,694 \\
\hline Genetic gain & 4,521 & 5,016 & 5,145 & 5,441 & 7,340 \\
\hline Total output & 229,642 & 229,901 & 231,763 & 232,395 & 238,154 \\
\hline \multicolumn{6}{|l|}{ Variable costs $(€)$} \\
\hline Concentrates & 32,718 & 32,685 & 32,680 & 33,199 & 32,851 \\
\hline Fertilizer & 15,332 & 15,238 & 15,294 & 15,018 & 15,223 \\
\hline Veterinary costs & 7,997 & 7,928 & 7,970 & 7,654 & 7,878 \\
\hline AI and breeding & 2,507 & 3,256 & 3,657 & 5,747 & 7,554 \\
\hline Other & 15,865 & 15,590 & 15,754 & 14,540 & 15,404 \\
\hline Total variable costs & 74,419 & 74,697 & 75,355 & 76,158 & 78,911 \\
\hline \multicolumn{6}{|l|}{ Fixed costs $(€)$} \\
\hline Car, electric, phone & 7,457 & 7,465 & 7,463 & 7,547 & 7,490 \\
\hline Machinery costs ${ }^{2}$ & 32,480 & 32,265 & 32,393 & 31,468 & 32,141 \\
\hline Buildings and land ${ }^{3}$ & 13,654 & 13,622 & 13,642 & 13,497 & 13,600 \\
\hline Other overheads & 5,029 & 5,029 & 5,029 & 5,029 & 5,029 \\
\hline Total fixed costs & 58,621 & 58,382 & 58,527 & 57,541 & 58,260 \\
\hline \multicolumn{6}{|l|}{ 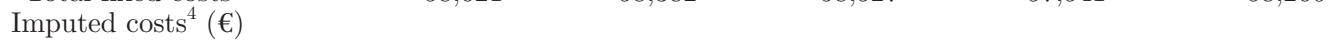 } \\
\hline Land charge & 19,535 & 19,418 & 19,488 & 19,154 & 19,402 \\
\hline Labor charge & 40,401 & 40,192 & 40,317 & 39,133 & 39,966 \\
\hline Capital charge & 11,401 & 11,380 & 11,414 & 11,225 & 11,368 \\
\hline Economic farm profit & 25,265 & 25,832 & 26,661 & 29,184 & 30,246 \\
\hline
\end{tabular}

${ }^{1}$ Fixed dairy herd size of 80 cows in all scenarios.

${ }^{2}$ Contractor charges, machinery operating, and depreciation.

${ }^{3}$ Improvements and maintenance on buildings and land.

${ }^{4}$ Imputed rent on own land, imputed on unpaid wages family labor, and imputed interest on own capital invested in the business.

genetic gain was a consequence of the higher selection intensity for TSEX-HC, TCONV-HC, TSEX-H, and TCONV-H relative to CONV. Concentrate and fertilizer costs reduced across all scenarios relative to CONV because TAI use improved the calving profile synchronizing grass supply and feed demand. Relative to CONV, the direct breeding costs (cost of materials only) increased substantially with the adoption of TAI and SS rising most (€5,047) under TSEX-HC. In comparison breeding costs relative to CONV increased by $€ 3,240, € 1,150$, and $€ 749$ for TCONV-HC, TSEX-H, and TCONV-H, respectively. Veterinary costs (excluding breeding-related treatments) were reduced across all the scenarios relative to CONV as fewer heifers were reared as replacements.

Figure 3 displays the cumulative distribution functions $(\mathbf{C D F})$ of the annual $\triangle \mathrm{PROF}$ per cow. A positive annual $\triangle \mathrm{PROF}$ per cow was observed from the adoption of TAI with unsorted or SS. The CDF show that herd level adoption of the reproductive technologies returned a greater annual $\triangle \mathrm{PROF}$ on average in comparison to heifers only. The cumulative distribution function of the annual $\triangle \mathrm{PROF}$ per cow for TCONV-
$\mathrm{HC}$ was further to the right than TCONV-H and thus more likely to have a greater annual $\triangle \mathrm{PROF}$ per cow than TCONV-H on average. However, TCONV-H also had less volatile annual $\triangle \mathrm{PROF}$ per cow, indicated by a steeper slope of the CDF relative to TCONV-HC indicating lower economic risk. In comparison, TCONV-H, TSEX-H, and TCONV-HC were more likely to result in a lower annual $\triangle \mathrm{PROF}$ per cow than TSEX-HC on average but they also had less volatile annual $\triangle \mathrm{PROF}$ per cow, indicated by a steeper slope of the CDF. We determined a $24 \%$ probability of TCONV-H returning an economic profit per cow that is less than or equal to CONV (i.e., $\triangle \mathrm{PROF} \leq 0$ ). Similarly, for TSEX-HC there was an $18 \%$ probability of not returning a positive annual $\triangle \mathrm{PROF}$ per cow. For TCONV-HC this was reduced to a $12 \%$ probability of not returning a positive annual $\triangle \mathrm{PROF}$ per cow. In comparison, we found we found a $3 \%$ probability of TSEX-H not returning a positive annual $\triangle \mathrm{PROF}$ per cow.

Figure 4 displays the sensitivity analysis of the hormonal costs on the annual $\triangle \mathrm{PROF}$ per cow in the TAI scenarios. The y-axis intercept defines the hormonal treatment cost at which the modeled scenarios would 
have an annual $\triangle \mathrm{PROF}$ per cow that is less than or equal to CONV. The graph shows that as the cost of the hormones increased, the annual $\triangle \mathrm{PROF}$ per cow decreased. When the hormone costs decreased to €31/ head, the mean annual $\triangle \mathrm{PROF}$ per cow for TCONVH, TSEX-H, TCONV-HC, and TSEX-HC were $€ 6.40$, $€ 16.50, € 44.51$, and $€ 52.12$, respectively. The probability that the scenarios would not return a positive annual $\triangle \mathrm{PROF}$ per cow decreased to $9,1,8$, and $12 \%$ for TCONV-H, TSEX-H, TCONV-HC, and TSEX-HC, respectively. In comparison when the hormone costs increased to $€ 51 /$ head the mean annual $\triangle \mathrm{PROF}$ per cow for TCONV-H, TSEX-H, TCONV-HC, and TSEX-HC were $€ 1.41$, €11.39, €23.68, and $€ 30.77$, respectively. The probability that the scenarios would not return a positive annual $\triangle \mathrm{PROF}$ per cow increased to $38,5,20$, and $23 \%$ for TCONV-H, TSEX-H, TCONV-HC, and TSEX-HC, respectively.

The relative sensitivities (measured by range of the mean) of the annual $\triangle \mathrm{PROF}$ values in each scenario according to the distributions of the key inputs are shown in Table 5. This table also displays the sensitivity rank order of the input variables under each scenario, based on their relative contributions to the variation in annual $\triangle \mathrm{PROF}$. The range in mean annual $\triangle \mathrm{PROF}$ for TCONV policies was most sensitive to the $\mathrm{P} / \mathrm{AI}$ of TAI. However, the range in mean annual $\triangle \mathrm{PROF}$ for TSEX policies was most sensitive to the relative $\mathrm{P} / \mathrm{AI}$ achieved with SS as a percentage of conventional. Across the reproductive scenarios, there were notable differences in the rank order of the input variables according to their relative contributions to the estimated variation

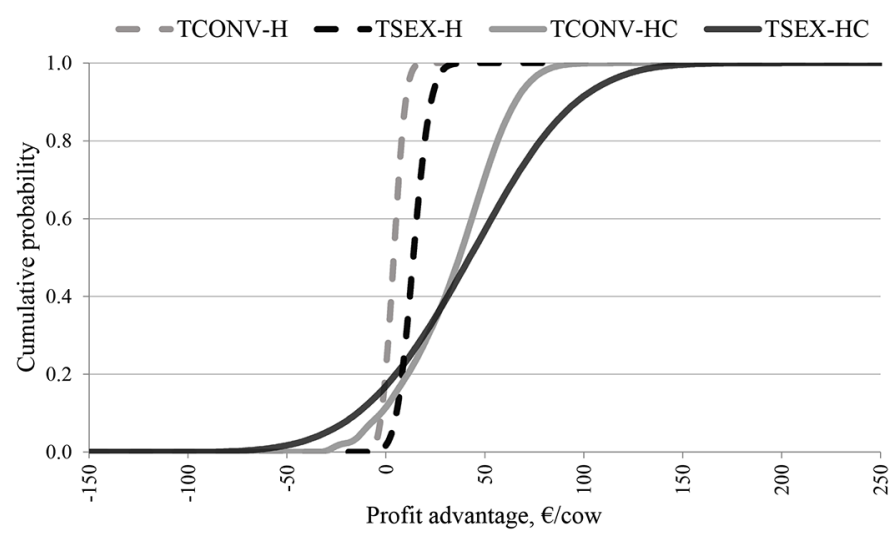

Figure 3. The profit advantage and variability in return $(€ /$ cow $)$ of using timed AI (TAI) with unsorted semen in heifers only with heifers and cows inseminated with conventional unsorted semen (TCONV-H), TAI in both heifers and cows and inseminated with conventional unsorted semen (TCONV-HC), TAI in heifers only with heifers inseminated with sexed semen and cows inseminated with conventional unsorted semen (TSEX-H), and TAI in both heifers and cows inseminated with sexed semen (TSEX-HC).

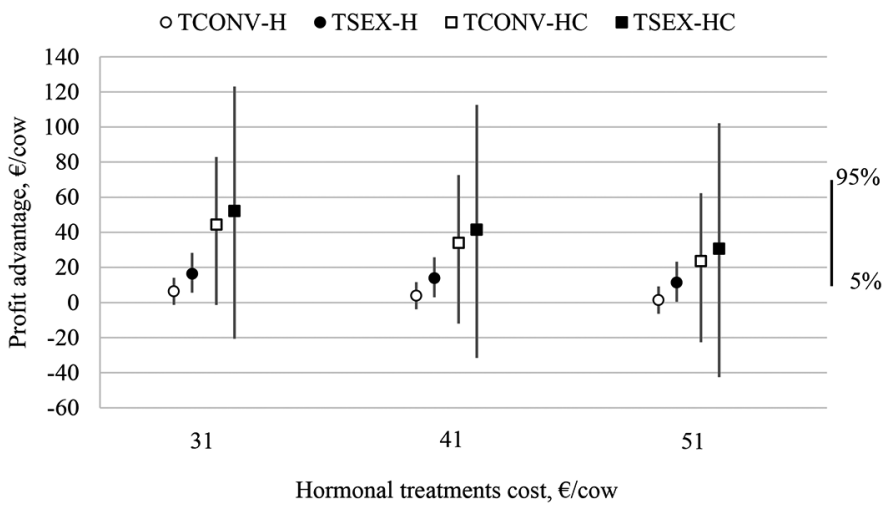

Figure 4. Sensitivity analysis of the hormonal treatment costs on the profit advantage per cow by using timed AI (TAI) with unsorted semen in heifers only with heifers and cows inseminated with unsorted semen (TCONV-H), TAI in both heifers and cows and inseminated with unsorted semen (TCONV-HC), TAI in heifers only with heifers inseminated with sexed semen and cows inseminated with unsorted semen (TSEX-H), and TAI in both heifers and cows inseminated with sexed semen (TSEX-HC). The error bars represent the 5th and 95th percentiles of the profit advantage.

in annual $\triangle \mathrm{PROF}$. Importantly, the level of sensitivity of the annual $\triangle \mathrm{PROF}$ to the key input variables, and therefore the financial risks associated with adoption of SS, increased sharply after adoption of TSEX across the whole herd compared with use on heifers only. For TSEX-HC, annual $\triangle$ PROF per cow was more than 7 times more sensitive than TSEX-H to both the P/AI of TAI and the SS P/AI as a percentage of conventional. In comparison, annual $\triangle \mathrm{PROF}$ per cow for TCONV$\mathrm{HC}$ was 6 times more sensitive than TCONV-H to the $\mathrm{P} / \mathrm{AI}$ of TAI. For TCONV reproductive scenarios, annual $\triangle \mathrm{PROF}$ per cow was most sensitive to the $\mathrm{P} / \mathrm{AI}$ of TAI, genetic gain, cull cow prices and milk solids. For TSEX reproductive scenarios annual $\triangle \mathrm{PROF}$ per cow was most sensitive to the $\mathrm{SS} \mathrm{P} / \mathrm{AI}$ as a percentage of conventional, $\mathrm{P} / \mathrm{AI}$ of TAI, genetic gain, and calf prices.

\section{DISCUSSION}

This study evaluated the economics of TAI with unsorted and SS in heifers only and both heifers and cows in comparison to CONV under a high herd fertility state in a seasonal, pasture-based, high-producing dairy production system. We found the annual $\triangle \mathrm{PROF}$ was greatest when TAI was used in heifers and cows in conjunction with SS semen. TAI boosted conception rates early in the breeding period helping to consolidate the calving pattern and, when combined with SS, partially offset lower P/AI associated with sorted semen. In the TAI with SS scenarios, the profit advantage was especially augmented by increased genetic gain and higher 


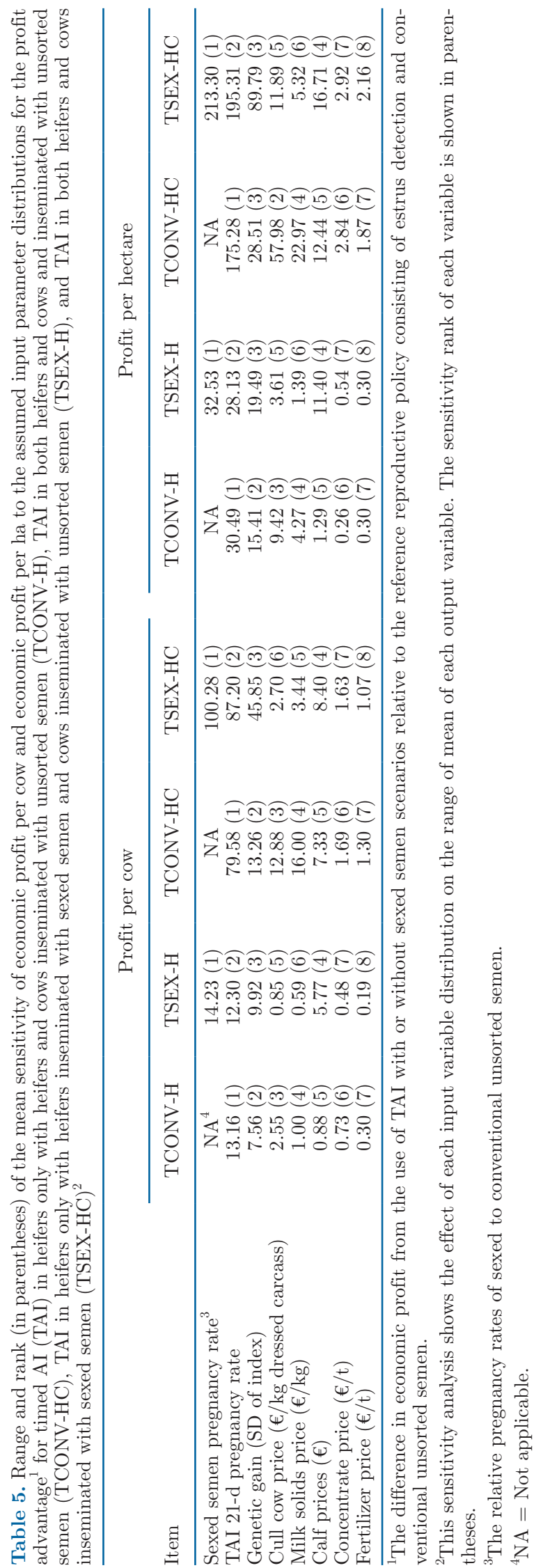

calf sales revenues. The economic implications of semen type when adopting a TAI protocol were found to depend primarily on the P/AI of TAI and the P/AI achieved with SS relative to conventional.

Calsamiglia et al. (2018) recommended that adoption of a TAI program depends on the baseline fertility of the herd under a control estrus detection and AI policy. The benefit of TAI followed the law of diminishing returns as the proportion of pregnant animals in the herd increased under the control policy with limited benefit of TAI at a P/AI of $30 \%$. Similarly, Tenhagen et al. (2004) found the benefit of adopting an Ovsynch protocol was greatest when implemented in a state of previously low estrus detection. However, Giordano et al. (2011) suggested that the improvement in reproductive performance fully compensated for the more expensive Double-Ovsynch protocol. Contrary to Calsamiglia et al. (2018) and Tenhagen et al. (2004) and in agreement with the hypothesis of Giordano et al. (2011), we found a substantial annual $\triangle \mathrm{PROF}$ could be made with the adoption of TAI under a high CONV fertility state $(95 \%$ estrus detection rate and a $55 \%$ pregnancy rate). The difference in our results compared with Calsamiglia et al. (2018) and Tenhagen et al. (2004) may be attributable to the greater economic importance of fertility in seasonal pasture-based systems. Conversely, with the adoption of SS, Walsh et al. (2021) and Seidel (2003) found dairy herds with already low reproductive performance using CONV are less likely to realize a financial advantage from sexed semen use as potentially reduced P/AI amplify existing fertility challenges. In less fertile herds adoption of TAI alone may return a positive annual $\triangle \mathrm{PROF}$ by increasing the proportion of cows bred earlier in the breeding period. However, TAI will not resolve issues regarding low sire fertility, and improper handling and placement of semen. Consequently, TAI in combination with SS use could further exacerbate existing profitability challenges in herds with already low fertility through increased breeding costs and further reduced $\mathrm{P} / \mathrm{AI}$.

Galvão et al. (2013) found that combining TAI and estrus detection increased profits within each level of accuracy of estrus detection and each level of compliance with the synchronization protocol. However, when evaluated separately, estrus detection at $60 \%$ with $95 \%$ accuracy or TAI with $95 \%$ compliance were as profitable as, or more profitable than, TAI and estrus detection with low estrus detection, accuracy, or compliance. Therefore, producers can improve their profits by combining TAI and estrus detection in their reproductive management strategy. However, herds with a high estrus detection and accuracy or a high compliance with treatment protocols may be more profitable using TAI or estrus detection in isolation 
rather than implementing both concurrently. In contrast, we found using TAI at the start of the breeding period to first service only and estrus detection in subsequent services returned a positive annual $\triangle \mathrm{PROF}$. It is difficult to precisely compare economic returns from TAI use between studies due to differences in financial and other modeling parameters. However, Calsamiglia et al. (2018) found a €64/cow per year profit advantage from TAI use, which is broadly within the range estimated by Galvão et al. (2013) of $\$ 46$ to $\$ 68 /$ cow per year. Our research on the economics of TAI with unsorted or SS in a pasture-based system has shown similar effects on the annual $\triangle \mathrm{PROF}$ of TCONV-HC and TSEX-HC, returning €34.11/cow and €41.52/cow per year, respectively. However, when used in heifers only this was reduced to $€ 3.90 /$ cow and $€ 13.96 /$ cow for TCONV-H and TSEX-H, respectively.

Silva et al. (2015) found TAI use in heifers increased the $\mathrm{P} / \mathrm{AI}$ and reduced the cost per pregnancy compared with a control estrus detection and AI policy. The cost per pregnancy for both reproductive policies only became similar when the insemination rate after the first $21 \mathrm{~d}$ breeding period was high and P/AI was low. Our sensitivity analysis indicated that the annual $\triangle \mathrm{PROF}$ of the TAI with unsorted semen reproductive policies was most sensitive to the P/AI of TAI. In comparison to Silva et al. (2015), we found that holding all other stochastic variables at their modal values and the $\mathrm{P} / \mathrm{AI}$ of TAI at the lower end of the distribution, an annual $\triangle \mathrm{PROF}$ per cow of approximately $€ 7.18$ would be attainable in TSEX-H and turning negative -€3.39 in TCONV-H.

Masello et al. (2021) concluded that TAI used in combination with estrus detection or TAI alone as the primary method to submit heifers for first service generated differences in cash flow of potential value to commercial dairy farms. Greater reproductive costs due to TAI use were offset by the positive effect of earlier pregnancy on cash flow of replacement heifers. Similar to Masello et al. (2021), we found that TAI for first service was economically more advantageous than CONV and that the higher upfront costs were offset by the improvement in the $\mathrm{P} / \mathrm{AI}$ early in the breeding period.

Ricci et al. (2020) found that despite the higher upfront cost incurred by using more hormonal treatments a Double-Ovsynch $+\mathrm{PGF}_{2 \alpha}$ program was more profitable than other synchronization programs, including a Presynch-Ovsynch program with $100 \%$ timed AI or a Presynch-Ovsynch program that incorporated estrus detection. Ricci et al. (2020) accredited the profit advantage of the Double-Ovsynch $+\mathrm{PGF}_{2 \alpha}$ program to the superior $\mathrm{P} / \mathrm{AI}$ reducing the number of cows resubmitted to a resynchronization program. Consequently, fewer hormonal treatments were required per pregnancy which decreased the total cost of the program. The advantage of a Double-Ovsynch $+\mathrm{PGF}_{2 \alpha}$ program remained until the cost of hormones was increased 5 to 14 times current US market prices and 2 to 6 times current European market prices (derived from Italy, the United Kingdom, and Germany; Ricci et al., 2020). However, these findings were based on a year-round calving system. The superior $\mathrm{P} / \mathrm{AI}$ of a Double-Ovsynch $+\mathrm{PGF}_{2 \alpha}$ program could offset the increased hormonal and labor costs and further consolidate the calving spread resulting in increased profitability in pasture-based systems. However, the duration of compliance to complete a Double-Ovsynch $+\mathrm{PGF}_{2 \alpha}$ program is $27 \mathrm{~d}$ in comparison to $10 \mathrm{~d}$ for a modified $\mathrm{P} 4-\mathrm{Ov}$ synch, and thus to achieve the superior $\mathrm{P} / \mathrm{AI}$ entails greater compliance costs due to the duration of the protocol. Moreover, in a seasonal system, a program requiring $27 \mathrm{~d}$ is too long. Therefore, trade-offs exist for a Double-Ovsynch $+\mathrm{PGF}_{2 \alpha}$ program regarding the increased P/AI versus increased hormonal and labor costs for an increased number of sequential injections and added complexity of the protocol. Consequently, further studies are needed to investigate the economics of alternative synchronization protocols, particularly in pasture-based systems.

Although not the focus of our analysis, targeted synchronization within dairy herds could increase the annual $\triangle \mathrm{PROF}$ of TAI with unsorted or sexed semen. Synchronization protocols such as a modified P4-Ovsynch could be targeted at anestrous cows and late-calving cows only to advance the time of rebreeding after calving. This would have beneficial effects on the subsequent herd calving pattern which is critical to the profitability of pasture-based systems. However, dairy farmers would have to identify anestrous cows before and during the breeding season to use synchrony effectively and improve the reproductive performance of these cows. To implement targeted synchronization would require accurate record keeping with high rates of estrus detection and accuracy to minimize false positive anestrous cows.

The effectiveness of sexed semen has been improved with advancements such as SexedULTRA (Sexing Technologies) designed to be less harmful to sperm during the various processes (Gonzalez-Marin et al., 2017; Lenz et al., 2017). Research of SexedULTRA in pasture-based dairy production systems at $4 \times 10^{6} \mathrm{SS}$ per dose from internationally shipped ejaculates indicated a relative pregnancy rate to conventional AI of $69 \%$ on average (Maicas et al., 2020). Conversely, dairy cows served with SexedULTRA SS from locally resident bulls onsite or near sex-sorting laboratories produced a relative pregnancy rate to conventional AI of $>81 \%$. Similarly, Drake et al. (2020) found the relative concep- 
tion rate of SS for locally resident bulls at $4 \times 10^{6}$ sperm per dose was $84 \%$ when used in combination with TAI. Holding all other stochastic variables at their modal values and the $\mathrm{SS} \mathrm{P} / \mathrm{AI}$ as a percentage of conventional at the lower end of this distribution $(67 \% \mathrm{SS} \mathrm{P} / \mathrm{AI}$ as a percentage of conventional) an annual $\triangle \mathrm{PROF}$ per cow of approximately €6.72 would still be attainable in TSEX-H and turning negative $(-€ 11.15)$ in TSEX-HC.

For TSEX-H and TSEX-HC, the relative P/AI of SS compared with conventional AI was the most critical parameter to the range in annual $\triangle$ PROF. Similar to Walsh et al. (2021) this parameter was associated with substantially greater financial variability when used in heifers and cows compared with heifers only (see Figure 3). The P/AI of SS relative to conventional AI had more effect on the annual $\triangle \mathrm{PROF}$ per cow in TSEX-HC (€100.28) than in TSEX-H (€14.23) with more SS doses being used in the TSEX-HC scenario. Walsh et al. (2021) reported that use of sexed semen in a fixed herd size in heifers and cows in a high herd fertility state with a modal SS pregnancy rate of $87 \%$ relative to conventional semen returned a substantial profit advantage ( $€ 49.14 /$ cow per year) over a conventional unsorted semen reproductive policy. Similarly, we found that in a fixed herd size TSEX-HC with a modal SS relative $\mathrm{P} / \mathrm{AI}$ of $84 \%$ to conventional semen returned a profit advantage relative to CONV. However, in comparison to Walsh et al. (2021), results of the current study indicate a similar annual $\triangle \mathrm{PROF}$ on average from TSEX-HC in contrast to SS use in heifers and cows without TAI. Our results showed a similar profit advantage on average despite the relative $\mathrm{P} / \mathrm{AI}$ of SS to unsorted semen in this analysis being 3 percentage points lower for the modal value (84 vs. $87 \%$ ) and 2 percentage points lower for the lower end of the distribution (67 vs. $69 \%$ ) in comparison to Walsh et al. (2021). Our research has shown that the relative pregnancy rate of SS to unsorted semen has a profound effect on the overall profitability and is the most sensitive parameter on the annual $\triangle \mathrm{PROF}$ in TSEX-H and TSEX-HC. Similarly, Walsh et al. (2021) found that the profit advantage from SS use in heifers and cows was most sensitive to the $\mathrm{P} / \mathrm{AI}$ of $\mathrm{SS}$ relative to unsorted semen followed by calf prices and genetic gain.

Achieving greater genetic gain through SS use depends on the availability of SS from the highest genetic merit bulls. In our analysis we assumed that SS from the best bulls was available. However, the demand for conventional semen straws is often greater than the supply and sorting of sperm results in significant sperm wastage; thus, the highest ranked bulls are often not sorted. The present circumstances may change if the marginal difference in dairy bull and heifer calf prices increases and farmers become more conscious of the benefits of SS use, as increased demand would encourage AI companies to supply sorted sperm from a wider range of bulls.

The contribution of calf sales was greater than the contribution of genetic gain to farm revenue across all reproductive policies. However, the monetary benefit from genetic gain through SS use is only obtained when the replacement heifers enter the milking herd several years after insemination and therefore is an investment for the future. Farmers may prefer the more immediate financial return from TAI use to stimulate anestrous cows to return to estrus and the improvement in the subsequent herd calving pattern rather than the delayed financial return from their investment in SS. The trade-offs between the current investment cost versus longer-term advantage are likely to influence farmers' decisions on SS and TAI use.

It is estimated that in the United States, $60 \%$ of all breeding age heifers are required just to maintain a fixed herd size, whereas $0.1 \%$ of male dairy calves are chosen to become dairy sires (De Vries et al., 2008). With the recent post milk quota expansion of the national dairy herd in Ireland, the price of dairy bull calves has declined, intensifying an economic and welfare concern for the dairy industry. The difference between dairy heifer and bull calf prices is a key determinant of the profit advantage of using SS (McCullock et al., 2013). If the price differential between dairy heifer calves and bulls increases the marginal return from adoption of SS also increases. It is worth noting that increased use of SS across the industry may negatively effect prices of dairy heifers due to potential excess supply (De Vries et al., 2008). Stangaferro et al. (2018) found the cost of a replacement heifer was the main contributor to the total variation in cashflow for lactating cows submitted for first service to TAI. Accordingly, increased use of beef semen is a complementary strategy alongside the use of sexed dairy semen. In the current study, SS use in a TAI protocol for heifers only or both heifers and cows can minimize the production of low value dairybreed male calves while increasing the annual $\triangle \mathrm{PROF}$ through increased calf sale values by servicing a higher portion of herds with beef semen. A reproductive policy with a combination of dairy SS and conventional beef semen has been shown to be an economically efficient strategy for Finnish and Irish dairy herds (Hietala et al., 2014; Walsh et al., 2021). Our results are consistent with these findings when SS is used in combination with a TAI protocol. Our analysis has shown that combined application of both technologies can return a greater annual $\triangle \mathrm{PROF}$ on average compared with that achievable from TAI alone.

Some limitations of our study are acknowledged concerning model specification and scenario assump- 
tions. First, the representation of system dynamics in the model using a monthly time step may not capture more subtle differences in the timings of reproductive events. For example, the more nuanced effects of TAI on the calving profile could be further evaluated using a more granular treatment of time using daily or weekly time steps. The added value of this enhanced precision needs to be weighed against the downsides of greater complexity and the concomitant data challenges in parameterization of a less parsimonious specification of system dynamics.

Second, the presentation of the reproductive scenarios in their long-term, steady-states neglected the near-term adjustment processes of the herd in its transition to the equilibrium. Farmers may prefer more immediate financial return to future profit potential, and the trade-off between the current investment cost and longer-term advantages are likely to influence their decisions about reproductive strategies. In this context, modeling farmers' individual time and risk preferences when discounting future cash flows become a critical consideration. These behavioral factors were considered to be outside the scope of the present analysis and the steady-state approach provided a pragmatic, consistent and tractable method for comparing the long-term economic potential of the reproductive strategies.

Third, specification of the scenarios involved certain simplifying assumptions. In particular, we limited our attention to pure (all or nothing) strategies. Consequently, an area of further development might focus on more flexible strategies based on refined criteria for more targeted application of the reproductive technologies within the herd. For example, De Vries (2019) indicates that the profit advantage of sex-sorted semen is likely to be greatest among the genetically superior females in the herd. Similarly, TAI could be used in a more flexible or targeted way including later application to consolidate at the end of the breeding period. Accordingly, targeted females would receive the TAI protocol and the resulting economic advantage could be higher than with a less focused approach.

\section{CONCLUSIONS}

Adoption of TAI and SS have the potential to increase profitability in high-producing pasture-based dairy systems. TAI with or without SS had the largest annual $\triangle \mathrm{PROF}$ when used in heifers and cows compared with heifers only, indicating that herd level adoption of these reproductive technologies can be advantageous. However, the adoption of TAI with or without SS in heifers only has been identified as a lower risk strategy to increasing economic profitability of pasture-based dairy production systems. The annual $\triangle \mathrm{PROF}$ of TAI with unsorted semen was most sensitive to the $\mathrm{P} / \mathrm{AI}$ of TAI whereas TAI with SS was most sensitive to the SS P/AI as a percentage of conventional. Use of TAI with SS facilitates more rapid genetic progress through increased selection intensity. From a farm management perspective, TAI alleviates the labor requirement for estrus detection and has been shown to be most profitable in combination with SS use in high-producing pasture-based dairy systems.

\section{ACKNOWLEDGMENTS}

The authors thank Enterprise Ireland (Dublin, Ireland) for partial funding of this project through the European Regional Development Fund. The authors have not stated any conflicts of interest.

\section{REFERENCES}

Bittante, G., R. Negrini, M. Bergamaschi, A. Cecchinato, and H. Toledo-Alvarado. 2020. Pure-breeding with sexed semen and crossbreeding with semen from double-muscled sires to improve beef production from dairy herds: Weight and value of calves. J. Dairy Sci. 103:5258-5262. https://doi.org/10.3168/jds.2019-18011.

Borchardt, S., A. Pohl, P. D. Carvalho, P. M. Fricke, and W. Heuwieser. 2018. Effect of adding a second prostaglandin F2 $\alpha$ injection during the Ovsynch protocol on luteal regression and fertility in lactating dairy cows: A meta-analysis. J. Dairy Sci. 101:8566-8571. https://doi.org/10.3168/jds.2017-14191.

Bord Bia. 2021. Irish Cattle Prices. Accessed Feb. 10, 2021. https: //www.bordbia.ie/farmers-growers/prices-markets/cattle-trade -prices/.

Butler, S. T., I. A. Hutchinson, A. R. Cromie, and L. Shalloo. 2014. Applications and cost benefits of sexed semen in pasture-based dairy production systems. Animal 8:165-172. https://doi.org/10 $.1017 /$ S1751731114000664.

Calsamiglia, S., S. Astiz, J. Baucells, and L. Castillejos. 2018. A stochastic dynamic model of a dairy farm to evaluate the technical and economic performance under different scenarios. J. Dairy Sci. 101:7517-7530. https://doi.org/10.3168/jds.2017-12980.

Carvalho, P. D., V. G. Santos, J. O. Giordano, M. C. Wiltbank, and P. M. Fricke. 2018. Development of fertility programs to achieve high 21-day pregnancy rates in high-producing dairy cows. Theriogenology 114:165-172. https://doi.org/10.1016/j.theriogenology .2018.03.037.

Central Bank of Ireland. 2018. Retail interest rates. Central Bank of Ireland. Accessed Oct. 15, 2018. https://www.centralbank.ie/ statistics/data-and-analysis/credit-and-banking-statistics/retail -interest-rates.

Central Statistics Office. 2021. Agricultural input and output absolute prices. Accessed Feb. 21 2021. https://www.cso.ie/en/statistics/ agriculture/agriculturalpriceindices/.

Cottle, D. J., M. Wallace, P. Lonergan, and A. G. Fahey. 2018. Bioeconomics of sexed semen utilization in a high-producing HolsteinFriesian dairy herd. J. Dairy Sci. 101:4498-4512. https://doi.org/ 10.3168/jds.2017-13172.

De Vries, A. 2019. The economics of sexed semen in dairy heifers and cows. Institute of Food and Agricultural Sciences Extension, University of Florida, Gainesville. Accessed Jan. 23, 2020. http://edis ifas.ufl.edu/an214.

De Vries, A., M. Overton, J. Fetrow, K. Leslie, S. Eicker, and G. Rogers. 2008. Exploring the impact of sexed semen on the structure of the dairy industry. J. Dairy Sci. 91:847-856. https://doi.org/10 .3168/jds.2007-0536. 
Deming, J., D. Gleeson, T. O'Dwyer, J. Kinsella, and B. O'Brien. 2018. Measuring labor input on pasture-based dairy farms using a smartphone. J. Dairy Sci. 101:9527-9543. https://doi.org/10 $.3168 /$ jds.2017-14288.

Donnellan, T., B. Moran, J. Lennon, and E. Dillon. 2020. Teagasc National Farm Survey 2019 Results. Teagasc. https://www.teagasc .ie/media/website/publications/2020/Teagasc-National-Farm -Survey-2019.pdf.

Drake, E., S. A. Holden, V. Aublet, R. C. Doyle, C. Millar, S. G. Moore, C. Maicas, F. Randi, A. R. Cromie, P. Lonergan, and S. T. Butler. 2020. Evaluation of delayed timing of artificial insemination with sex-sorted sperm on pregnancy per artificial insemination in seasonal-calving, pasture-based lactating dairy cows. J. Dairy Sci. 103:12059-12068. https://doi.org/10.3168/jds.2020-18847.

Galvão, K. N., P. Federico, A. De Vries, and G. M. Schuenemann. 2013. Economic comparison of reproductive programs for dairy herds using estrus detection, timed artificial insemination, or a combination. J. Dairy Sci. 96:2681-2693. https://doi.org/10.3168/ jds.2012-5982.

Giordano, J. O., P. M. Fricke, M. C. Wiltbank, and V. E. Cabrera. 2011. An economic decision-making support system for selection of reproductive management programs on dairy farms. J. Dairy Sci. 94:6216-6232. https://doi.org/10.3168/jds.2011-4376.

Gonzalez-Marin, C., R. W. Lenz, T. B. Gilligan, K. M. Evans, C. E. Gongora, J. F. Moreno, and R. Vishwanath. 2017. 191 SexedULTRA $^{\mathrm{TM}}$, a new method of processing sex sorted bovine sperm improves post-thaw sperm quality and in vitro fertility. Reprod. Fertil. Dev. 29:204. https://doi.org/10.1071/RDv29n1Ab191.

Herlihy, M. M., D. P. Berry, M. A. Crowe, M. G. Diskin, and S. T. Butler. 2011. Evaluation of protocols to synchronize estrus and ovulation in seasonal calving pasture-based dairy production systems. J. Dairy Sci. 94:4488-4501. https://doi.org/10.3168/jds $.2010-4126$

Hietala, P., P. Bouquet, and J. Juga. 2014. Effect of replacement rate, crossbreeding and sexed semen on the efficiency of beef production from dairy herds in Finland. Acta Agric. Scand. A Anim. Sci. 64:199-209. https://doi.org/10.1080/09064702.2015.1013978.

Hutchinson, I. A., L. Shalloo, and S. T. Butler. 2013. Expanding the dairy herd in pasture-based systems: The role of sexed semen use in virgin heifers and lactating cows. J. Dairy Sci. 96:6742-6752. https://doi.org/10.3168/jds.2012-6476.

Irish Cattle Breeding Federation. 2020. Dairy calving statistics 2010-2020. Accessed Feb 26, 2021. https://www.icbf.com/wp/wp -content/uploads/2020/10/Dairy-Calving-Stats-PDF-1.pdf.

Irish Cattle Breeding Federation. 2021. Latest EBI reports. Accessed Feb 26, 2021. https://www.icbf.com/wp/?p=15663.

Irish Farmers Journal. 2019. Summary of calf prices. Irish Farmers J 72:64-65.

Jarrige, R. 1989. Ruminant nutrition: recommended allowances and feed tables. John Libbey Eurotext.

Lenz, R. W., C. Gonzalez-Marin, T. B. Gilligan, J. M. DeJarnette, M. D. Utt, L. A. Helser, E. Hasenpusch, K. M. Evans, J. F. Moreno, and R. Vishwanath. 2017. 190 SexedULTRA $^{\mathrm{TM}}$, a new method of processing sex-sorted bovine sperm improves conception rates. Reprod. Fertil. Dev. 29:203-204. https://doi.org/10.1071/ RDv29n1Ab190.

Madalena, F. E., and F. S. Junqueira. 2004. The value of sexed bovine semen. J. Anim. Breed. Genet. 121:253-259. https://doi.org/10 $.1111 /$ j.1439-0388.2004.00463.x.

Maher, P., M. Good, and S. J. More. 2008. Trends in cow numbers and culling rate in the Irish cattle population, 2003 to 2006. Ir. Vet. J. 61:455-463. https://doi.org/10.1186/2046-0481-61-7-455.

Maicas, C., S. A. Holden, E. Drake, A. R. Cromie, P. Lonergan, and S. T. Butler. 2020. Fertility of frozen sex-sorted sperm at $4 \times 10^{6}$ sperm per dose in lactating dairy cows in seasonal-calving pasturebased herds. J. Dairy Sci. 103:929-939. https://doi.org/10.3168/ jds.2019-17131.

Maicas, C., I. A. Hutchinson, J. Kenneally, J. Grant, A. R. Cromie, P. Lonergan, and S. T. Butler. 2019. Fertility of fresh and frozen sex-sorted semen in dairy cows and heifers in seasonal-calving pasture-based herds. J. Dairy Sci. 102:10530-10542. https://doi .org/10.3168/jds.2019-16740.

Masello, M., M. M. Perez, G. E. Granados, M. L. Stangaferro, B. Ceglowski, M. J. Thomas, and J. O. Giordano. 2021. Effect of reproductive management programs for first service on replacement dairy heifer economics. J. Dairy Sci.104471-485.

McCullock, K., D. L. K. Hoag, J. Parsons, M. Lacy, G. E. Seidel Jr., and W. Wailes. 2013. Factors affecting economics of using sexed semen in dairy cattle. J. Dairy Sci. 96:6366-6377. https://doi.org/ 10.3168/jds.2013-6672.

Meadows, C., P. J. Rajala-Schultz, and G. S. Frazer. 2005. A spreadsheet-based model demonstrating the nonuniform economic effects of varying reproductive performance in Ohio dairy herds. J. Dairy Sci. 88:1244-1254. https://doi.org/10.3168/jds.S0022 -0302(05)72791-0.

Noonan, E. J., J. C. Kelly, and D. S. Beggs. 2016. Factors associated with fertility of nulliparous dairy heifers following a 10-day fixedtime artificial insemination program with sex-sorted and conventional semen. Aust. Vet. J. 94:145-148. https://doi.org/10.1111/ avj. 12430

O’Sullivan, M., B. Horan, K. M. Pierce, S. McParland, K. O'Sullivan, and F. Buckley. 2019. Milk production of Holstein-Friesian cows of divergent Economic Breeding Index evaluated under seasonal pasture-based management. J. Dairy Sci. 102:2560-2577. https:// doi.org/10.3168/jds.2018-15559.

Ojeda-Rojas, O. A., A. M. Gonella-Diaza, M. F. Sá Filho, R. Nunes, and A. H. Gameiro. 2018. A simulation model to evaluate the economic consequences of insemination programs in dairy herds: timed artificial insemination and sex-sorted semen. Rev. Bras. Zootec. 47:e20170344. https://doi.org/10.1590/rbz4720170344.

Progressive Genetics. 2021. Bull semen for dairy sires. Accessed Feb 24, 2021. https://www.progressivegenetics.ie/.

Pursley, J. R., and J. P. N. Martins. 2011. Impact of circulating concentrations of progesterone and antral age of the ovulatory follicle on fertility of high-producing lactating dairy cows. Reprod. Fertil. Dev. 24:267-271. https://doi.org/10.1071/RD11917.

Pursley, J. R., M. O. Mee, and M. C. Wiltbank. 1995. Synchronization of ovulation in dairy cows using PGF $2 \alpha$ and GnRH. Theriogenology 44:915-923. https://doi.org/10.1016/0093-691X(95)00279-H.

Randi, F., J. M. Sánchez, M. M. Herlihy, A. Valenza, D. A. Kenny, S. T. Butler, and P. Lonergan. 2018. Effect of equine chorionic gonadotropin treatment during a progesterone-based timed artificial insemination program on reproductive performance in seasonalcalving lactating dairy cows. J. Dairy Sci. 101:10526-10535. https: //doi.org/10.3168/jds.2018-14495.

Redman, G. 2016. John Nix Farm Management Pocketbook. 47th ed. Agro Business Consultants Ltd.

Ricci, A., M. Li, P. M. Fricke, and V. E. Cabrera. 2020. Economic impact among 7 reproductive programs for lactating dairy cows, including a sensitivity analysis of the cost of hormonal treatments. J. Dairy Sci. 103:5654-5661. https://doi.org/10.3168/jds.2019-17658.

Rivera, F. A., L. G. Mendonça, G. Lopes Jr., J. E. Santos, R. V. Perez, M. Amstalden, A. Correa-Calderón, and R. C. Chebel 2011. Reduced progesterone concentration during growth of the first follicular wave affects embryo quality but has no effect on embryo survival post transfer in lactating dairy cows. Reproduction 141:333-342. https://doi.org/10.1530/REP-10-0375.

Ryan, T. 2018. Estimating farm building costs. Teagasc Agriculture and Food Development Authority, https://www.teagasc.ie/rural -economy/farm-management/farm-buildings/animal-housing/ estimating-farm-building-costs/.

Sánchez, J. M., F. Randi, C. Passaro, D. J. Mathew, S. T. Butler, and P. Lonergan. 2018. Effect of human chorionic gonadotrophin administration 2 days after insemination on progesterone concentration and pregnancy per artificial insemination in lactating dairy cows. J. Dairy Sci. 101:6556-6567. https://doi.org/10.3168/ jds.2017-14058.

Seidel, G. E. Jr., 2003. Economics of selecting for sex: the most important genetic trait. Theriogenology 59:585-598. https://doi.org/10 .1016/S0093-691X(02)01242-6. 
Shalloo, L., A. Cromie, and N. McHugh. 2014. Effect of fertility on the economics of pasture-based dairy systems. Animal 8(Suppl 1):222231. https://doi.org/10.1017/S1751731114000615.

Silva, T. V., F. S. Lima, W. W. Thatcher, and J. E. P. Santos. 2015. Synchronized ovulation for first insemination improves reproductive performance and reduces cost per pregnancy in dairy heifers. J. Dairy Sci. 98:7810-7822. https://doi.org/10.3168/jds.2015-9704.

Society of Chartered Surveyors Ireland \& Teagasc. 2020. Land market review and outlook 2020. Accessed Feb 17, 2021. https://www .teagasc.ie/news-events/news/2020/scsiteagasc-agricultural.php.

Souza, A. H., P. A. Carvalho, R. D. Shaver, M. C. Wiltbank, and V. E. Cabrera. 2013. Impact of timed AI use on reproductive performance and culling rate in Wisconsin dairy herds. J. Anim. Sci. 91:W303.

Stangaferro, M. L., R. Wijma, M. Masello, M. J. Thomas, and J. O. Giordano. 2018. Economic performance of lactating dairy cows submitted for first service timed artificial insemination after a voluntary waiting period of 60 or 88 days. J. Dairy Sci. 101:75007516. https://doi.org/10.3168/jds.2018-14484.

Stewart, G. B. 2003. How to fix accounting-measure and report economic profit. Bank Am. J. Appl. Corp. Finance 15:63-82. https:/ /doi.org/10.1111/j.1745-6622.2003.tb00461.x.

Teagasc. 2018. Profit Monitor Analysis Dairy Farms. Teagasc. Accessed Mar 2, 2020. https://www.teagasc.ie/media/website/ publications/2019/eProfit-Book-2018.pdf.
Tenhagen, B. A., M. Drillich, R. Surholt, and W. Heuwieser. 2004 Comparison of timed AI after synchronized ovulation to AI at estrus: Reproductive and economic considerations. J. Dairy Sci. 87:85-94. https://doi.org/10.3168/jds.S0022-0302(04)73145-8.

University College Dublin. 2020. 3 Yearly Report on UCD Lyons Systems Herd. Accessed Feb 2, 2020. https://www.ucd.ie/lyonsfarm/ t4media/3\%20Yearly\%20Report\%20on\%20UCD\%20Lyons $\% 20$ Systems\%20Herd.pdf

Walsh, D. P., A. G. Fahey, F. J. Mulligan, and M. Wallace. 2021. Effects of herd fertility on the economics of sexed semen in a highproducing, pasture-based dairy production system. J. Dairy Sci. 104:3181-3196. https://doi.org/10.3168/jds.2020-18676.

\section{ORCIDS}

D. P. Walsh ( ) https://orcid.org/0000-0002-3800-5021

A. G. Fahey ๑ https://orcid.org/0000-0002-4594-5767

P. Lonergan (1) https://orcid.org/0000-0001-5598-5044

M. Wallace @ https://orcid.org/0000-0002-3616-8919 